\title{
DTI tractography and MRI in chronic cerebral ischemia in rhesus monkey (Macaca mulatta) in vivo
}

DTI tratografia e RM em isquemia cerebral crônica em macaco rhesus (Macaca mulatta) in vivo Axayacatl Morales-Guadarrama1,2, Iván Mejía-González', Braulio Hernández-Godínez,4, Alejandra Ibáñez-Contreras ${ }^{3,4}$, Sergio A. Reyes-Pantoja ${ }^{3,4}$, Roberto Olayo²

An eight-year-old rhesus monkey (Macaca mulatta) presented an ischemic attack in the subcortical region of the right temporal area, naturally acquired by a hypoglycemic shock, generating asphyxia and arterial hypotension at 6 months old.

MRI performed showed ischemia in the right parietal lobe (Fig 1), from the injury focus in the middle cerebral artery, in the cerebral branches (insular and opercular branches) (Fig 2). The loss of continuity in the nerve fibers can be seen through the tractography, corresponding to encephalomalacic changes (Fig 3$)^{1,2}$.

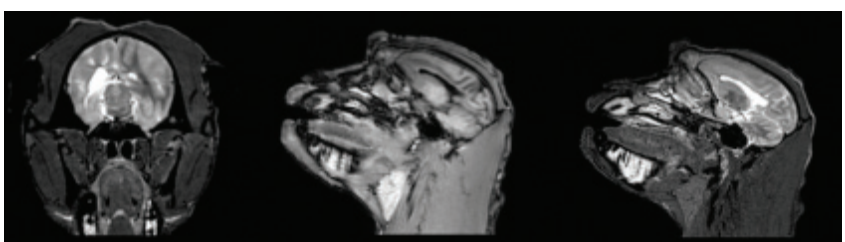

Fig 1. (A) Composited T2 weighted image shows the hyperintense signal in the right hemisphere corresponding to the ischemic area, (B) the sagittal T1 weighted image shows an hipointense signal and his absence in the same lesion area, contrasted with (C) sagittal T2 weighted image with the hyperintense signal corresponding the ischemic area.

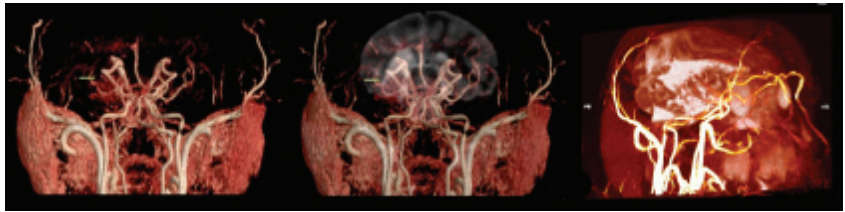

Fig 2. (A) The MR Angiography indicates stenosis in the middle cerebral artery (green arrow) being the injury's core. The angiography's joint with the T2 weighted image (B) indicates the injury's core with a green arrow. The 3D reconstruction (C) allows noting the size of the injury area (hyperintense signal in the hemisphere)

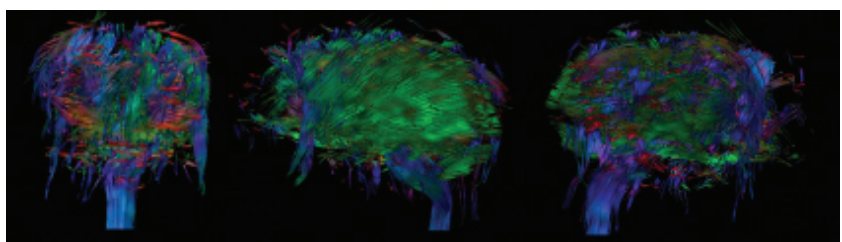

Fig 3. Tractography obtained by diffusion tensor image DTI displays in the frontal view (A) a full brain perspective. In the left lateral view (B), we can observe the healthy zone with high integrity and order in the projected tracts (green lines) while in the right lateral view the injury area is shown (C), and clearly presents white matter architecture destruction in this area, which corresponds to encephamlomalacic changes.

References

Burgener FA, Meyers SP, Tan RK, Zaunbauer W. Diagnóstico diferencial mediante resonancia magnética. Buenos Aires: Ediciones Journal 2005. p. 30-31.
Singh M, Jeong J, Hwang D, Sungkarat W, Gruen P. Novel diffusion
tensor imaging methodology to detect and quantify injured regions
and affected brain pathways in traumatic brain injury. Magn Reson Imaging 2010;28:22-40.

\footnotetext{
'Centro Nacional de Investigación en Instrumentación e Imagenología Médica (CI3M). Universidad Autónoma Metropolitana - Unidad Iztapalapa (UAM-I) Ciudad de México, México;

2Departamento de Ingeniería Eléctrica, Universidad Autónoma Metropolitana - Unidad Iztapalapa (UAM-I) Ciudad de México, México;

${ }^{3}$ Centro de Investigación, Proyecto CAMINA, A.C, Unidad de Primate; Ciudad de México, México;

${ }^{4}$ BIOINVERT ${ }^{\oplus}$. Biología Integral para Vertebrados: Unidad de Experimentación Animal, Edo. México, México.

Correspondence: Axayacatl Morales-Guadarrama; San Rafael Atlixco. 186, Col. Vicentina; DF.09340 Iztapalapa - México; E-mail: axa_mx@yahoo.com

Support: Projects CONACyT - 155239, ICy-T-DF-PIUTE 10-63, 276/2010

Conflict of interest: There is no conflict of interest to declare.

Received 30 August 2012; Received in final form 14 August 2012; Accepted 21 August 2012
} 